\title{
An Efficient and Novel Regioselective Synthesis of Phosphonylpyrazoles from Vinylazides and Bestmann-Ohira Reagent
}

\author{
ARAVINDA KUMAR MADUGULA ${ }^{1}$, VAITHIYANATHAN MAHENDRAN², \\ AJJANNA MAHALINGAPPA SRIDHARA ${ }^{3}$ and GURURAJA RANGAIAH ${ }^{1 *}$
}

\begin{abstract}
${ }^{1}$ Centre for Research and Development, PRIST University, Thanjavur 613403, Tamilnadu, India. ${ }^{2}$ Department of Organic Chemistry, Madurai Kamaraj University, Madurai 625021, Tamil Nadu, India. ${ }^{3}$ Gomti Life sciences India Pvt Ltd, Bidadi Industrial Area, Bangalore-562 109, India.

${ }^{*}$ Corresponding author E-mail: dr.gururaja @gmail.com
\end{abstract}

http://dx.doi.org/10.13005/ojc/320524

(Received: September 08, 2016; Accepted: October 14, 2016)

\begin{abstract}
A novel and efficient reaction of vinyl azides with Bestmann-Ohira reagent for the regioselective synthesis of phosphonylpyrazoles is presented. Reaction proceeds through 1, 3 dipolar cycloaddition with an excellent yield in short period of time under mild reaction conditions. Moreover, no column purification is involved for the isolation of products.
\end{abstract}

Keywords: Phosphonylpyrazoles, Vinylazides, 1,3-dipolar cycloaddition, Regioselectivity, Bestmann-Ohira reagent.

\section{INTRODUCTION}

The Bestmann-Ohira reagent (BOR, dialkyl á-diazo-â-oxopropylphosphonate) a modified version of Seyferth-Gillbert reagent, ${ }^{1}$ is well known and an efficient reagent for the homologation of aldehydes to terminal alkynes under gentle basic conditions. ${ }^{2}$ It is readily prepared by commercially available sources. ${ }^{3}$ Recently, the BOR has found new applications in organic chemistry for the synthesis of several phosphonylated heterocycles ${ }^{4}$ using range of dipolarophiles through 1, 3 dipolar cycloaddition reaction. Due to their structural complexity and high biological activity, synthesis of several heterocycles compounds such as phosphonyloxazoles and pyrazoles ${ }^{5}$ have been reported in the literature using the Bestmann-Ohira reagent (BOR) as the cycloaddition partner. ${ }^{6}$ The heterocyclic compounds play a vital role in pharmaceutical chemistry. Among them pyrazoles have indispensable role over the past due to their good biologically activity and their properties in heterocycles. Pyrazoles occupy a central stage due to their wide applications in the pharmaceutical industry, agrochemicals and biological agents, and also play a central role in coordination chemistry. ${ }^{7,8}$ Few biologically active molecules containing pyrazole scaffold, such as Withasomnine, Acomplia, Celecoxib, Lonazolac, 
Diphenamizole (Analgesic), Doramapimod and Viagra show evidence of important therapeutic potential. In addition, agrochemical active ingredients such as Penthiopyrad (Fungicide) and Fipronil (Insecticide) etc. also contain pyrazole scaffold and few of them are shown in (Fig-1).

Literature survey reveals the presence of variety of methods for the synthesis of pyrazoles and its derivatives. Traditional approaches are based on either condensation of hydrazine with 1, 3-dicarbonyl compounds for the formation of two C-N bonds or the cycloaddition reaction of 1,3-dipoles to triple bonds. ${ }^{9,10}$

Recently, phosphonylpyrazoles have shown significant role in medicinal chemistry due to their structural intricacy and high biological activities. Various methods for the synthesis of phosphonylpyrazoles have been reported in literature using BOR. ${ }^{11}$

A methodology using BOR as cycloaddition partner with various nitro alkenes for the regioselective synthesis of phosphonylpyrazoles under mild reaction condition was first reported by Namboothiri et al. in 2007..$^{12,13}$ Later, Mohanan and co-workers ${ }^{14}$ developed a novel convergent multi component reaction using BOR. Based on a domino Knoevenagel condensation of formal 1,3-dipolar cycloaddition reaction, the three-component reaction of aldehydes, BOR and cyanoacetic derivatives generates 5-phosphonylpyrazole scaffolds through the formation of two $\mathrm{C}-\mathrm{C}$ and $\mathrm{C}-\mathrm{N}$ bonds. Martin and co-workers ${ }^{15}$ further broaden the emerging role of the BOR as 1,3-dipolar precursor by developing a

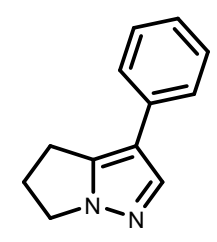

Withasomine (Analgesic \& CNS depressant)<smiles>O=C(O)Cc1cn(-c2ccccc2)nc1-c1ccc(Cl)cc1</smiles>
(Anti- inflammatory)

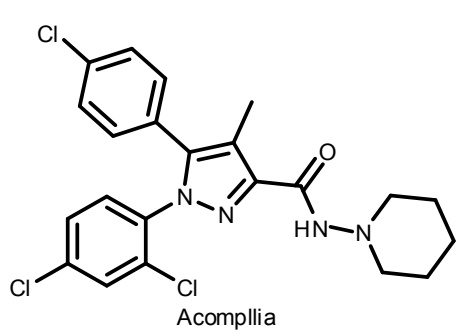

(Cannabinoid receptor CB1)

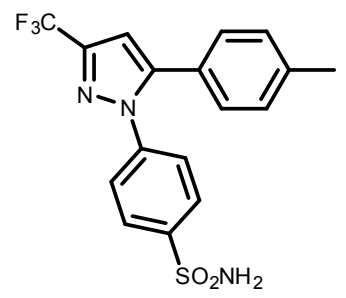

Celecoxib

(Anti- inflammatory)<smiles>CC(C(=O)Nc1cc(-c2ccccc2)nn1-c1ccccc1)N(C)C</smiles>

Diphenamizole (Analgesic)<smiles>CCCc1nn(C)c2c(=O)[nH]c(-c3cc(S(=O)(=O)N4CCN(C)CC4)ccc3OCC)nc12</smiles>

(Erectile dysfunction \& PAH)<smiles>CC(C)CC(C)c1sccc1NC(=O)c1cn(C)nc1C(F)(F)F</smiles><smiles>Cc1ccc(-n2nc(C(C)(C)C)cc2NC(=O)Nc2ccc(OCCN3CCOCC3)c3ccccc23)cc1</smiles>

p-38 MAP kinase inhibitor)<smiles>Nc1nn(-c2c(Cl)cc(C(F)(F)F)cc2Cl)c(N)c1S(=O)C(F)(F)F</smiles>

Fig. 1: Biologically active molecules containing pyrazole scaffold 
more general and straight forward procedure for the regioselective preparation of 3-carbo-5-phosphonyl pyrazoles. Authors reported an unprecedented Claisen-Schmidt/1,3-dipolar cycloaddition/oxidation sequence for an aldehyde, methyl ketone and the BOR in one-pot reaction step afford good yields of phosphonylpyrazoles. There are plenty of options for the development of new methodologies where BOR will find application for the construction of other unexplored heterocyclic scaffolds found in a numerous useful natural products and synthetic compounds.

Vinyl azides are classified as organic azides, which are valuable reactants in organic synthesis. Nitrogen containing heterocyclic compounds are having key role in pharmaceutically active drug

\section{Table 1: Optimization of the reaction conditions for the synthesis of phosphonylpyrazoles by 1,3-dipolar cycloaddition reactions of vinylazides (1a) with Bestmann-Ohira reagent (2)}

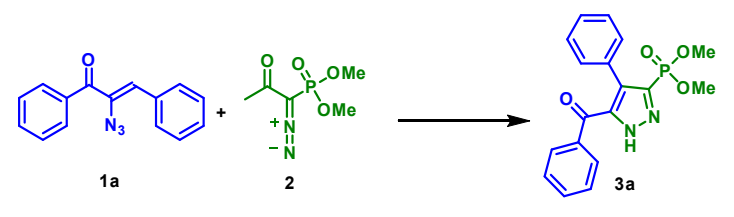

\begin{tabular}{lcccc}
\hline Entry & Base & Solvent & Time & Yield (\%) \\
\hline 1 & - & $\mathrm{MeOH}$ & $24 \mathrm{~h}$ & n.r. \\
2 & $\mathrm{NaOH}$ & $\mathrm{MeOH}$ & $30 \mathrm{~min}$ & $41 \%$ \\
3 & $\mathrm{KOH}$ & $\mathrm{MeOH}$ & $10 \mathrm{~min}$ & $86 \%$ \\
4 & $\mathrm{LiOH}$ & $\mathrm{MeOH}$ & $1 \mathrm{~h}$ & $63 \%$ \\
5 & $\mathrm{NaOMe}$ & $\mathrm{MeOH}$ & $1 \mathrm{~h}$ & $51 \%$ \\
6 & $\mathrm{~K}_{2} \mathrm{CO}_{3}$ & $\mathrm{MeOH}$ & $12 \mathrm{~h}$ & $35 \%$ \\
7 & $\mathrm{Cs}_{2} \mathrm{CO}_{3}$ & $\mathrm{MeOH}$ & $12 \mathrm{~h}$ & $18 \%$ \\
8 & $\mathrm{DIPEA}^{\mathrm{P}}$ & $\mathrm{MeOH}$ & $12 \mathrm{~h}$ & Traces \\
9 & $\mathrm{DBU}$ & $\mathrm{MeOH}$ & $12 \mathrm{~h}$ & $46 \%$ \\
10 & $\mathrm{KOH}$ & $\mathrm{EtOH}$ & $30 \mathrm{~min}$ & $64 \%$ \\
11 & $\mathrm{KOH}$ & $\mathrm{THF}$ & $12 \mathrm{~h}$ & $21 \%$ \\
12 & $\mathrm{KOH}$ & $\mathrm{DMSO}$ & $12 \mathrm{~h}$ & $\mathrm{n} . \mathrm{r}$. \\
13 & $\mathrm{KOH}$ & $\mathrm{ACN}$ & $12 \mathrm{~h}$ & n. r. \\
\hline
\end{tabular}

${ }^{\mathrm{a}}$ General reaction performed conditions: 1a (1.0 $\mathrm{mmol}), 2$ (2.5 m mol), base $(2.5 \mathrm{~m} \mathrm{~mol})$, solvent 10 $\mathrm{ml}$ and temperature at $25^{\circ} \mathrm{C}$. ${ }^{\mathrm{b}}$ Isolated yield after crystallization with MTBE molecules and natural products. Recently, vinyl azides have been used as a pivotal three-atom synthon for the formation of diverse nitrogen based heterocycles. ${ }^{16}$ The unique properties of the azide group connected to an alkene moiety permit this functional group to act as an electrophile, a nucleophile, or a radical acceptor, and have turned these compounds into indispensable building blocks for organic synthesis. One of the intriguing chemical features of vinyl azides is the ability to undergo thermolysis or photolysis to give highly strained three-membered $2 \mathrm{H}$-azirines which can be regarded as equivalents of vinyl nitrenes. In this context, we envisaged the formation of phosphonyl pyrazoles from the reaction of vinyl azide and BOR. Thus, we present here the development of a novel synthetic methodology for the synthesis of phosphonylpyrazole by using base mediated 1, 3-dipolar cycloaddition reaction of vinyl azides ${ }^{17}$ with the Bestmann-Ohira reagent. The new synthetic approaches using BOR have been developed with the aim of increasing yields, regioselectivities, and operational simplicity. However, with best of our knowledge, base mediated 1, 3-dipolar cycloaddition reaction of vinyl azides

Table 2: Substrate scope for the synthesis of phosphonylpyrazoles (3)

\begin{tabular}{lcccc}
\hline & & & & \\
\end{tabular}

a General reaction performed conditions: 1a (1.0 $\mathrm{mmol}), 2$ (2.5 m mol), $\mathrm{KOH}(2.5 \mathrm{~m} \mathrm{~mol})$, Methanol $(10 \mathrm{ml})$ and temperature at $25-30^{\circ} \mathrm{C}$. 


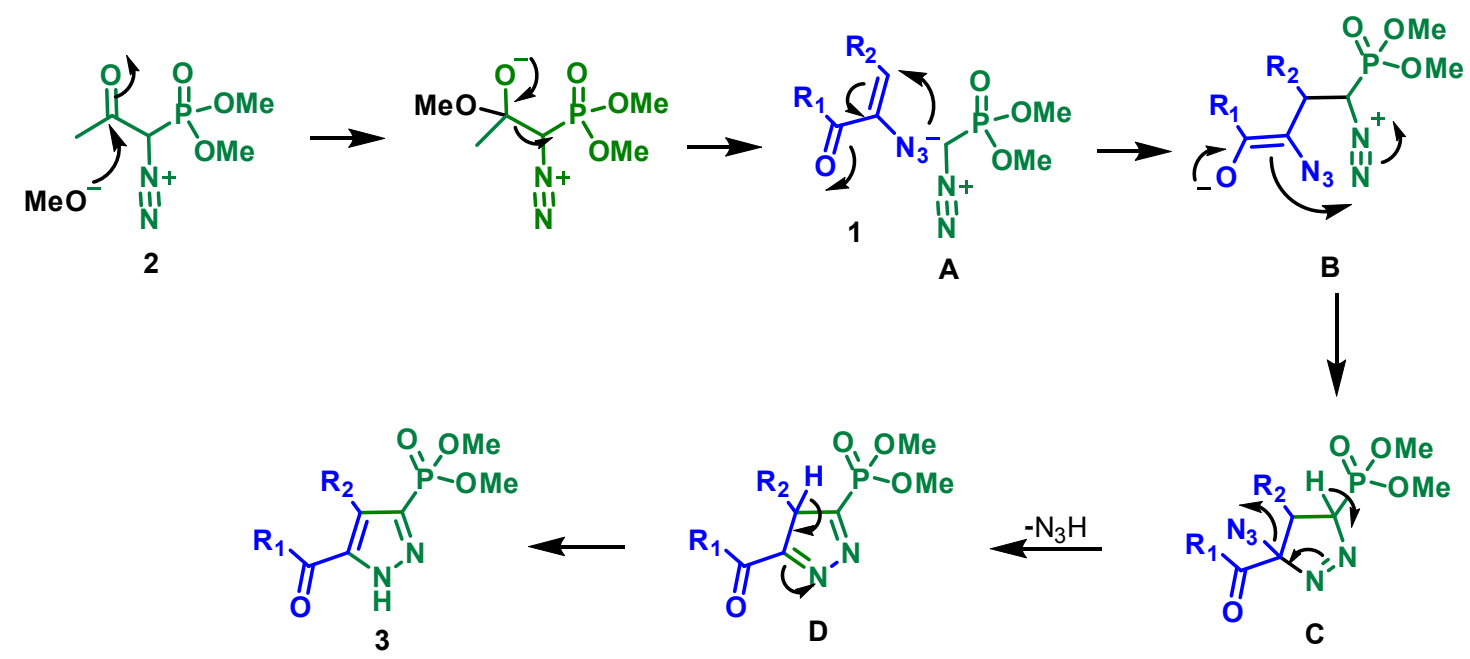

Fig. 2: Proposed mechanism of the reaction

with the Bestmann-Ohira reagent has not been documented in the literature during the study.

\section{RESULT AND DISCUSSION}

We have initiated synthesis of proposed phosphonylpyrazoles with simple vinyl azide (1a) and BOR (2). The optimization of this synthetic strategy was planned in the presence of various organic and inorganic bases and several protic and aprotic solvents at room temperature and the corresponding results are tabulated in the Table 1. It was observed that no phosphonylpyrazole was produced in absence of base even after carrying out the reaction for long period of time in dry methanol (Table-1, entry-1). However, the similar reactionof1awith BOR (2) in presence of inorganic base $\mathrm{NaOH}$ at room temperature in an open air, produced the desired product $(3 \mathrm{a})$ in $30 \mathrm{~min}$. with $41 \%$ yield (Table- 1 , entry-2). The reaction was highly regioselective. The desired product was further confirmed by Mass, ${ }^{1} \mathrm{HNMR}$ and ${ }^{13} \mathrm{CNMR}$ analysis. Since the result was slightly encouraging, we attempted the use of several other inorganic bases such as $\mathrm{KOH}, \mathrm{LiOH}, \mathrm{NaOMe}, \mathrm{K}_{2} \mathrm{CO}_{3}$ and $\mathrm{Cs}_{2} \mathrm{CO}_{3}$ in methanol as a solvent of choice at room temperature in an open air to obtain the product with average to excellent yields (Table-1, entry 3-7). Among all the bases examined, $\mathrm{KOH}$ given the highest yield of $86 \%$ in shorter reaction time with single regioisomer (Table 1, entry 3 ), whereas organic bases such as
DBU \& Diisopropylethylamine (DIPEA) in methanol at room temperature produced very low to moderate yields; After 12 hrs of reaction $46 \%$ with DBU and observed traces of product after $12 \mathrm{hrs}$ of reaction with DIPEA (Table-1, entry 8 \& 9). Several protic and aprotic solvents were also used for the optimization of reaction using $\mathrm{KOH}$ as a base. It was observed that, only $64 \%$ and $21 \%$ product was formed using ethanol and THF as solvents respectively (Table-1, entry 10 \& 11). In addition, no product was formed in the reactions of DMSO and $\mathrm{ACN}$ as solvents even after 12 hrs of reaction (Table-1, entry 12 \& 13). After all these optimization studies, it was decided to carry out the synthesis of phosphonylpyrazole derivatives by reacting 1 ( $1 \mathrm{mmol}$ ) and $2(2.5 \mathrm{mmol})$ using $\mathrm{KOH}$ $(2.5 \mathrm{mmol})$ as base in methanol $(10 \mathrm{~mL})$ at room temperature as optimized reaction conditions.

After successfully optimizing the reaction conditions, various phosphonylpyrazole derivatives were synthesized in very short period of time (10 to 20 minutes) with good yields. The reaction of $1 \mathrm{a}$ and BOR under the optimized reaction condition completed in just $10 \mathrm{~min}$. to obtain the desired product Dimethyl [5-Benzoyl-4-phenyl-1H-pyrazol$3-y l$ phosphonate (3a) in $86 \%$ yield. The scope of the reacting substrates were analysed by using vinyl azide derivatives with several functional groups. Accordingly, the vinyl azide derivatives1b, $1 \mathrm{e}$ and $1 \mathrm{f}$, with electron donating groups such as methoxy, methyl groups were reacted with BOR 
to obtain the corresponding pyrazole derivatives $3 \mathrm{~b}, 3 \mathrm{e}$ and $3 f$ in 10 minutes, and in $79 \%, 76 \%$, and $72 \%$ yields respectively. In addition, the pyrazole derivatives $3 \mathrm{i}$ and $3 \mathrm{j}$ with chlorine substituent were also produced from $1 \mathrm{i}$ and $1 \mathrm{j}$ in just $10-15 \mathrm{~min}$. with the yields of $79 \%$ and $77 \%$ respectively. Interestingly, the phosphonylpyrazole derivatives with fluorine atoms $3 \mathrm{c}$ and $3 \mathrm{~g}$ were obtained in $10 \mathrm{~min}$. while $3 \mathrm{k}$ was obtained in $15 \mathrm{~min}$. with the yields of $67 \%$, $63 \%$ and $69 \%$ respectively. Similarly, indole derived vinylazide substrates $1 \mathrm{~d}, 1 \mathrm{~h}$ and $1 \mathrm{l}$ were successfully reacted to BOR to furnish the corresponding pyrazole derivatives $3 \mathrm{~d}$, 3h and $3 \mathrm{l}$ in 15-20 min. in good yields of $71 \%, 74 \%$ and $62 \%$ respectively.

On the basis of these results, a tentative mechanism for the formation of novel phosphonylpyrazoles is proposed and is illustrated in Figure-2. The initial step involves the methanolysis of BOR which would generate diazomethyl phosphonate anion (A). The vinylazide (1) would then be attacked by diazomethyl phosphonate anion $(A)$ followed by cyclization via $B$ leads to cyclic system $C$. The elimination of hydrazoic acid $\left(\mathrm{N}_{3} \mathrm{H}\right)$ from $\mathrm{C}$ results in to the formation of cyclic system $D$ which then rearranges via proton transfer to a more stable aromatic pyrazole derivative 3 .

\section{Experimental section}

General information: All the reactions were conducted in oven dried glass ware. The reagents were all analytically pure. All solvents were purified dried by standard methods in advance. ${ }^{1} \mathrm{H}$ NMR spectra were recorded on a VARIAN Mercury-Plus $400 \mathrm{MHz}$ spectrometer in $\mathrm{CDCl}_{3}$ or DMSO- $\mathrm{d}_{6}$ with TMS as the internal reference. ${ }^{13} \mathrm{C}$ NMR spectra were recorded in $\mathrm{CDCl}_{3}$ or DMSO- $\mathrm{d}_{6}$ on a Varian Mercury-Plus (100/150 MHz) spectrometer and chemical shifts $(\delta)$ are given in ppm. Unless otherwise specified, all reactions were carried out under an air atmosphere in oven dried RB flasks. Dimethyl2-oxopropylphosphonate was purchased from commercial sources for the synthesis of BestmannOhira reagent and synthesised vinyl azides ${ }^{17}$. The reactions were monitored by TLC and visualized by UV ${ }_{254} \mathrm{~nm}$. MS spectra were determined using a Trace MS 2000 organic mass spectrometry, and the signals were given in $\mathrm{m} / \mathrm{z}$. Melting points were taken on a Buchi B-545 melting point apparatus and were uncorrected. All the commercially available reagents were used as received.

\section{General procedure for the synthesis of phosphonyl pyrazoles using Bestmann-Ohirareagent (3a-I)}

To an oven-dried round bottom flask was added vinyl azides $1 \mathrm{a}-\mathrm{I}(1.0 \mathrm{mmol})$ dissolved in 10 $\mathrm{mL}$ of $\mathrm{MeOH}$. Subsequently, a solution of BestmannOhira reagent $(2.5 \mathrm{mmol})$ in $5 \mathrm{~mL}$ of $\mathrm{MeOH}$ was added to the reaction mixture and was kept stirring. After the addition of $\mathrm{KOH}(2.5 \mathrm{mmol})$, the reaction mixture was stirred at room temperature for a specified time. After the completion of reaction, as indicated by TLC, the solvent was evaporated and the crude reaction mixture was extracted by using ethyl acetate. The organic layer was dried over $\mathrm{Na}_{2} \mathrm{SO}_{4}$ and evaporated under reduced pressure. The residue was purified by using ter-butyl methyl ether to get the desired products $3 \mathrm{a}-\mathrm{I}$.

\section{Dimethyl [5-Benzoyl-4-phenyl-1H-pyrazol-3-yl] phosphonate(3a)}

Yield: $86 \%$;Off-white solid; $\mathrm{mp}: 152-154{ }^{\circ} \mathrm{C}$; 1H NMR (400 MHz, DMSO-d6) $\delta: 3.58$ (d, J = 11.6 $\mathrm{Hz}, 6 \mathrm{H}), 7.29$ (s, 5H), 7.45 (br s, 3H), 7.59 (br s, 1H), 7.86 (br s, 1H), 14.49 (br s, 1H); 13C NMR (100 MHz, DMSO-d6) $\delta: 53.4$ (d, Jc-p = 5.4 Hz, CH3), 127.8, $127.9,128.0,128.7,130.3,131.1,133.6$; MS [M+H]+ 356.8

Dimethyl [5-Benzoyl-4-(4-methoxyphenyl)-1Hpyrazol-3-yl]phosphonate(3b)

Yield: $79 \%$; Off-white solid; $\mathrm{mp}$ : $187-189^{\circ} \mathrm{C}$; 1H NMR (400 MHz, DMSO-d6) $\delta: 3.58$ (d, $J=11.2$ $\mathrm{Hz}, 6 \mathrm{H}), 3.73(\mathrm{~s}, 3 \mathrm{H}), 6.85(\mathrm{~d}, J=8.4 \mathrm{~Hz}, 2 \mathrm{H}), 7.23$ (d, $J=8.8 \mathrm{~Hz}, 2 \mathrm{H}), 7.45(\mathrm{~m}, 2 \mathrm{H}), 7.60$ (t, J =7.2 Hz, 1H), 7.81 (s, 2H), 14.41 (br s, 1H); 13C NMR (100 $\mathrm{MHz}, \mathrm{DMSO}-\mathrm{d} 6) \delta$ : 53.4 (d, Jc- $p=5.4 \mathrm{~Hz}, \mathrm{CH} 3$ ), 55.4, 113.5, 123.1, 128.7, 130.3, 131.5, 133.5, 137.3, 159.1, 188.4; MS [M+H]+ 386.8.

Dimethyl [5-Benzoyl-4-(4-fluorophenyl)-1Hpyrazol-3-yl]phosphonate (3c)

Yield: 67\%; Off-white solid; mp: 182-184

${ }^{\circ} \mathrm{C}$; 1HNMR (400 MHz, $\mathrm{CDCl}_{3}$ ) $\delta: 3.69$ (d, $J=11.6$ $\mathrm{Hz}, 6 \mathrm{H}), 7.01(\mathrm{t}, \mathrm{J}=8.4 \mathrm{~Hz}, 2 \mathrm{H}), 7.33-7.39(\mathrm{~m}, 4 \mathrm{H})$, 7.52 (t, $J=7.6 \mathrm{~Hz}, 1 \mathrm{H}), 7.92$ (br s, 2H); 13C NMR $\left(100 \mathrm{MHz}, \mathrm{CDCl}_{3}\right) \delta: 53.4(\mathrm{~d}, J c-p=5.4 \mathrm{~Hz})$ 114.8, 115.0, 126.2, 126.3, 128.1, 130.3, 131.7, 131.7, 133.1, 136.7, 161.3, 163.7; MS [M+H]+374.8. 
Dimethyl [5-Benzoyl-4-(Indole-3-yl)-1H-pyrazol3-yl]phosphonate(3d)

Yield: 71\%; Off-white solid; $\mathrm{mp}: 228-230^{\circ} \mathrm{C}$; 1H NMR (400 MHz, DMSO-d6) $\delta: 3.55$ (d, J=11.2 $\mathrm{Hz}, 6 \mathrm{H}), 6.84$ (s, 1H), 7.02-7.08 (m, 2H), 7.34-7.54 (m, 5H), 7.84 (br s, 2H), $11.17(\mathrm{~s}, 1 \mathrm{H}), 14.40(\mathrm{~s}, 1 \mathrm{H})$; 13C NMR (100 MHz, DMSO-d6) $\delta: 53.3$ (d, Jc-p = $6.2 \mathrm{~Hz}), 104.7,111.8,119.2,121.3,125.7,127.1$, $128.5,128.6,130.1,130.3,133.4,136.2 ; \mathrm{MS}[\mathrm{M}+\mathrm{H}]+$ 396.0

Dimethyl [5-(4-methylbenzoyl)-4-phenyl-1Hpyrazol-3-yl]phosphonate (3e)

Yield: $76 \%$; Off-white solid; $\mathrm{mp}: 148-150^{\circ} \mathrm{C}$; 1H NMR (400 MHz, DMSO-d6) $\delta: 2.35$ (s, 3H), 3.57 (d, $J=11.6 \mathrm{~Hz}, 6 \mathrm{H}), 7.29-7.31(\mathrm{~m}, 8 \mathrm{H}), 7.74$ (br s, 2H), 14.44 (br s, 1H); 13C NMR (100 MHz, DMSOd6) $\delta: 53.4(\mathrm{~d}, J c-p=6.2 \mathrm{~Hz}), 127.8$ 128.0, 129.3, 130.2, 130.5, 131.2, 144.2; MS [M+H]+370.8.

Dimethyl [5-(4-methylbenzoyl)-4-(4methoxyphenyl)-1H-pyrazol-3-yl]phosphonate (3f)

Yield: $72 \%$; Off-white solid; $\mathrm{mp}: 185-187^{\circ} \mathrm{C}$; 1HNMR (400 MHz, $\left.\mathrm{CDCl}_{3}\right) \delta: 2.36(\mathrm{~s}, 3 \mathrm{H}), 3.68$ (d, J $=11.6 \mathrm{~Hz}, 6 \mathrm{H}), 3.80(\mathrm{~s}, 3 \mathrm{H}), 6.84(\mathrm{~d}, J=8.4,2), 7.16$ (d, $J=7.6 \mathrm{~Hz}, 2 \mathrm{H}), 7.31(\mathrm{~d}, J=8.8 \mathrm{~Hz}, 2 \mathrm{H}), 7.84$ (d, $J=7.6 \mathrm{~Hz}, 2 \mathrm{H})$ ); $13 \mathrm{C}$ NMR (100 MHz, DMSO-d6) $\delta: 53.3(\mathrm{~d}, J c-p=6.2 \mathrm{~Hz}), 55.4,113.5,123.2,129.1$, 129.3, 130.4, 131.4, 134.7, 144.1, 159.0, 188.0; MS $[\mathrm{M}+\mathrm{H}]+400.8$.

Dimethyl [5-(4-methylbenzoyl)-4-(4-fluorophenyl)1H-pyrazol-3-yl]phosphonate (3g)

Yield: $63 \%$; Off-white solid; $\mathrm{mp}: 159-161^{\circ} \mathrm{C}$; 1HNMR (400 MHz, $\left.\mathrm{CDCl}_{3}\right) \delta: 2.38$ (s, 3H), 3.69 (d, $J=11.6 \mathrm{~Hz}, 6 \mathrm{H}), 7.01(\mathrm{t}, 8.4 \mathrm{~Hz}, 2 \mathrm{H}), 7.17(\mathrm{~d}, J=$ $6.8 \mathrm{~Hz}, 2 \mathrm{H}), 7.36$ (q, $5.6 \mathrm{~Hz}, 2 \mathrm{H}), 7.86(\mathrm{~s}, 2 \mathrm{H}) ; 13 \mathrm{C}$ NMR (100 MHz, DMSO-d6) $\delta: 51.1$ (d, Jc-p = 5.4 $\mathrm{Hz}), 114.0,114.3,124.4,124.5,129.1,129.8,129.9$, 130.6, 132.4, 132.4, 135.7, 141.0, 143.4, 160.1, 162.5, 189.7; MS [M+H]+ 389.0.

Dimethyl [5-(4-methylbenzoyl)-4-(Indole-3-yl)-1Hpyrazol-3-yl]phosphonate (3h)

Yield: 74\%; Off-white solid; $\mathrm{mp}: 211-213^{\circ} \mathrm{C}$; $1 \mathrm{H}$ NMR (400 MHz, DMSO-d6) $\delta: 2.32$ (s, 3H), 3.54 (d, $J=11.2 \mathrm{~Hz}, 6 \mathrm{H}), 6.82(\mathrm{t}, J=7.6 \mathrm{~Hz}, 1 \mathrm{H}), 6.98-$ $7.06(\mathrm{~m}, 2 \mathrm{H}), 7.21(\mathrm{br} \mathrm{s}, 2 \mathrm{H}), 7.34(\mathrm{~d}, J=8 \mathrm{~Hz}, 1 \mathrm{H})$, 7.42 (s, 1H) 7.75 (br s, 2H), 11.29 (s, 1H), 14.36 (br s, $1 \mathrm{H})$; 13C NMR (100 MHz, DMSO-d6) $\delta: 53.3(\mathrm{~d}$, $J c-p=5.5 \mathrm{~Hz}), 104.7,111.9,119.0,119.1,121.2$, 125.7, 127.2, 129.2, 130.3, 134.7, 136.2, 143.9; MS $[\mathrm{M}+\mathrm{H}]+410.0$.

Dimethyl [5-(4-chlorobenzoyl)-4-phenyl-1Hpyrazol-3-yl] phosphonate (3i)

Yield: 79\%; Off-white solid; mp: 155$157^{\circ} \mathrm{C}$; $1 \mathrm{HNMR}\left(400 \mathrm{MHz}, \mathrm{CDCl}_{3}\right) \delta: 3.66$ (d, $J=11.6 \mathrm{~Hz}, 6 \mathrm{H}), 3.68(\mathrm{~s}, 3 \mathrm{H}), 7.34(\mathrm{~m}, 7 \mathrm{H})$, $7.91(\mathrm{~m}, 2 \mathrm{H}) ; 13 \mathrm{C} N M R(100 \mathrm{MHz}, \mathrm{CDCl} 3)$ $\delta: 53.4(\mathrm{~d}, J c-p=5.5 \mathrm{~Hz}), 127.9,128.1,128.4,129.8$, $130.4,130.3,130.6,130.8,131.8,131.9,135.2$, 139.4, 186.9; MS [M+H]+388.9.

Dimethyl [5-(4-chlorobenzoyl)-4-(4methoxyphenyl)-1H-pyrazol-3-yl]phosphonate (3j)

Yield: 77\%; Off-white solid; mp: 196-198 C; 1HNMR (400 MHz, $\left.\mathrm{CDCl}_{3}\right) \delta$; $3.68(\mathrm{~d}, J=11.6 \mathrm{~Hz}$, $6 \mathrm{H}), 3.81$ (s, 3H), 6.87 (d, J= $8.8 \mathrm{~Hz}, 2 \mathrm{H}), 7.29-7.35$ (m, 4H), 7.92 (br s, 2H); 13C NMR (100 MHz, CDCl ${ }_{3}$ ) $\delta: 53.4(\mathrm{~d}, J c-p=6.2 \mathrm{~Hz}), 55.1,113.4,122.3,128.3$, 131.1, 131.8, 135.3, 139.3, 159.4, 187.1; MS [M+H]+ 420.7 .

Dimethyl [5-(4-chlorobenzoyl)-4-(4-fluorophenyl)1H-pyrazol-3-yl]phosphonate (3k)

Yield: $69 \%$; Off-white solid; $\mathrm{mp}: 185-187^{\circ} \mathrm{C}$; 1HNMR (400 MHz, $\left.\mathrm{CDCl}_{3}\right) \delta ; 3.68(\mathrm{~d}, J=11.2 \mathrm{~Hz}, 6 \mathrm{H})$, $7.04(\mathrm{t}, J=8.8 \mathrm{~Hz}, 2 \mathrm{H}), 7.34-7.37(\mathrm{~m}, 4 \mathrm{H}), 7.95(\mathrm{br}$ s, 2H), 13.34 (br s, 1H); 13C NMR (100 MHz, CDCl ${ }_{3}$ ) $\delta: 53.4(\mathrm{~d}, J c-p=5.4 \mathrm{~Hz}), 114.8,115.0,126.3,126.3$, $128.4,129.6,129.8,131.6,131.5,131.8,135.2$, $139.5,161.3,163.7,186.9 ; \mathrm{MS}[\mathrm{M}+\mathrm{H}]+409.0$

Dimethyl [5-(4-chlorobenzoyl)-4-(Indole-3-yl)-1Hpyrazol-3-yl]phosphonate (3I)

Yield: $62 \%$; Off-white solid; $\mathrm{mp}: 226-228^{\circ} \mathrm{C}$; $1 \mathrm{H}$ NMR (400 MHz, DMSO-d6) $\delta: 3.54$ (d, $J=11.2$ $\mathrm{Hz}, 6 \mathrm{H}), 6.84(\mathrm{t}, J=7.6 \mathrm{~Hz}, 1 \mathrm{H}), 7.0-7.05(\mathrm{~m}, 2 \mathrm{H})$, 7.21 (br s, 2H), 7.34 (d, J=8 Hz, 1H), 7.42-7.45 (m, 3H) 7.85 (br s, 2H), 11.23 (s, 1H), 14.46 (br s, 1H); 13C NMR (100 MHz, DMSO-d6) $\delta: 53.3$ (d, Jc- $p=5.4$ $\mathrm{Hz}), 104.6,111.9,119.1,119.2,121.4,122.9,123.1$, 125.6, 125.7, 125.8, 127.1, 128.6, 129.3, 131.9, 136.0, 136.2, 138.2, 187.1; MS [M+H]+ 430.0. 


\section{CONCLUSIONS}

We have successfully developed an efficient, straight forward method for the synthesis of phosphonylpyrazole derivatives by base mediated 1,3-dipolar cyclo addition reaction between vinyl azides and Bestmann-Ohira reagent. Salient features of this methodology are short reaction time, mild reaction conditions, simple workup, column free purification and high yield. Further, the investigation of applications of BOR as cycloaddition partner for the synthesis of other new heterocycles is underway in our research group.

\section{ACKNOWLEDGEMENTS}

The Author Aravinda Kumar Madugula thankful to Department of Studies in Chemistry, Sharadavilas College, Mysore., and Dr. Mahagundappa Rachappa Maddani, Assistant Professor, Mangalore university, India for his support to the research.

\section{REFERENCES}

1. (a) Gilbert, J. C.; Weerasooriya, U. J. Org. Chem. 1982, 47, 1837-1845. (b) Seyferth, D.; Marmor, R. S.; Hilbert, P. J. Org. Chem. 1971, 36, 1379-1386.

2. (a) Shangguan, N.; Kiren, S.; Williams. L. J. Org. Lett. 2007, 9, 1093-1096. (b) Dickson, H. D.; Smith, S. C.; Hinkle, K. W. Tetrahedron Lett. 2004, 45, 5597-5599. (c) Dirat, O.; Clipson, A.; Elliott, J. M.; Garrett, S.; Jones, A. B.; Reader, M.; Shaw, D. Tetrahedron Lett. 2006, 47, 1729-1731. (d) Kramer, C. S.; Zeitler, K.; Muller, T. J. J. Org. Lett. 2000, 2, 3723-3726. (e) Roth, G. J.; Liepold, B.; Muller, S. G.; Bestmann, H. J. Synthesis. 2004, 59-62. (f ) Torssell, S.; Wanngren, E.; Somfai, P. J. Org. Chem. 2007, 72, 4246-4249. (g) Quesada, E.; Raw, S. A.; Reid, M.; Roman, E.; Taylor, R. J. K. Tetrahedron. 2006, 62, 6673-6680. (h) Lepage, O.; Kattnig, E.; Furstner, A. J. Am. Chem. Soc. 2004, 126, 15970-15971. (i) Pietruszka, J.; Witt, A.; Frey, W. Eur. J. Org. Chem. 2003, 3219-3229. ( j) Furstner, A.; Bouchez, L. C.; Funel, J.; Liepins, V.; Poree, F.; Gilmour, R.; Beaufils, F.; Laurich, D.; Tamiya, M. Angew. Chem. Int. Ed. 2007, 46, 92659270. (k) Vintonyak, V. V.; Maier, M. E. Angew. Chem. Int. Ed. 2007, 46, 5209-5211.

3. (a) Habrant, D.; Rauhala, V.; Koskinen, A. M. P. Chem. Soc. Rev. 2010, 39, 2007-2017. (b) Baxendale, I. R.; Ley, S. V.; Mansfield, A. C.; Smith, C. D. Angew. Chem. Int. Ed. 2009, 48,
4017. (c) Luvino, D.; Amalric, C.; Smietana, M.; Vasseur, J. J. Synlett. 2007, 3037-3041. (d) Quesada, E.; Raw, S. A.; Reid, M.; Roman, E.; Taylor, R. J. K. Tetrahedron. 2006, 62, 6673-6680. (e) Ohira, S. Synth. Commun. 1989, 19, 561-564. (f) Seyferth, D.; Marmor, R. S.; Hilbert, P. J. Org. Chem. 1971, 36, 13791386.

4. For use of BOR in the synthesis of phosphonylated heterocycles, see: (a) Connell, R.; Seavo, F.; Helquist, P.; Akermark, B. Tetrahedron Lett. 1986, 27, 5559-5562. (b) Gong, D.; Zhang, L.; Yuan, C. Synth. Commun. 2004, 34, 3259-3264. (c) Patil, . D. Synlett. 2009, 17, 2880-2881. (d) Mohapatra, S.; Bhanja, C.; Jena, S.; Chakroborty, S.; Nayak, S. Synth. Commun. 2013, 43, 1993-2007

5. Muruganantham, R.; Mobin, S. M.; Namboothiri, I. N. N. Org. Lett. 2007, 9, 1125-1128.

6. (a) Mohanan, K.; Martin, A. R.; Toupet, L.; Smietana, M.; Vasseur, J. Angew. Chem. Int. Ed. 2010, 49, 3196-3199. (b) Martin, A. R.; Mohanan, K.; Toupet, L.; Vasseur, J. J.; Smietana, M. Eur. J. Org. Chem. 2011, 17, 3184-3190. (c) Verma, D.; Mobin, S. M.; Namboothiri, I. N. N. J. Org. Chem. 2011, 76, 4764-4770. (d) Kumar, R.; Verma, D; Mobin, S. M.; Namboothiri, I. N. N. Org. Lett. 2012, 14, 4070-4073. (e) Kumar, R.; Nair, D.; Namboothiri, I. N. N. Tetrahedron, 2014, 70, 1794-1799. (f) Pramanik, M. M. D.; Kant, R.; 
Rastogi, N. Tetrahedron. 2014, 70, 52145220. (g) Ahamad, S.; Gupta, A. K.; Kant, R.; Mohanan, K. Org. Biomol. Chem. 2015, 13, 1492-1499.

7. (a) Fustero, S.; Roman, R.; Sanz-Cervera, J. F.; Simon-Fuentes, A.; Bueno, J.; Villanova, S. J. Org. Chem. 2008, 73, 8545-8552. (b) Vicentini, C. B.; Romagnoli, C.; Andreotti, E.; Mares, D. J. Agric. Food Chem. 2007, 55, 10331-10338. (c) Shiga, Y.; Okada, I.; Ikeda, Y.; Takizawa, E.; Fukuchi, T. J. Pestic. Sci. 2003, 28, 313-314. (d) Winters, M. P.; Subasinghe, N.; Wall, M.; Beck, E.; Brandt, M. R.; Finley, M. F. A.; Liu, Y.; Lubin, M. L.; Neeper, M. P.; Qin, N.; Flores, C. M.; Sui, Z. Bioorg. Med. Chem. Lett. 2014, 24, 2053-2056. (e) Dow, R. L.; Carpino, P. A.; Gautreau, D.; Hadcock, J. R.; Iredale, P. A.; Kelly-Sullivan, D.; Lizano, J. S.; O'Connor, R. E.; Schneider, S. R.; Scottand, D. O.; Ward, K. M. ACS Med. Chem. Lett. 2012, 3, 397-401. (f) Mowbray, C. E.; Burt, C.; Corbau, R.; Gayton, S.; Hawes, M.; Perros, M.; Tran, I.; Price, D. A.; Quinton, F. J.; Selby, M. D.; Stupple, P. A.; Webster, R.; Wood, A. Bioorg. Med. Chem. Let. 2009, 19, 5857-5860. (g) Wyatt, P. G.; Woodhead, A. J.; Berdini, V.; Boulstridge, J. A.; Carr, M. G.; Cross, D. M.; Davis, D. J.; Devine, L. A.; Early, T. R.; Feltell, R. E.; Lewis, E. J.; McMenamin, R. L.; Navarro, E. F.; O'Brien, M. A.; O’Reilly, M.; Reule, M.; Saxty, G.; Seavers, L. C. A.; Smith, D. M.; Squires, M. S.; Trewartha, G.; Walker, M. T.; Woolford, J. A. J. Med. Chem. 2008, 51, 4986-4999. (h) Regan, J.; Breitfelder, S.; Cirillo, P.; Gilmore, T.; Graham, A. G.; Hickey, E.; Klaus, B.; Madwed, J.; Moriak, M.; Moss, N.; Pargellis, C.; Pav, S.; Proto, A.; Swinamer, A.; Tong, L.; Torcellini, C. J. Med. Chem. 2002, 45, 2994-3008. (i) Ohki, H.; Hirotani, K.; Naito, H.; Ohsuki, S.; Minami, M.; Ejima, A.; Koiso, Y.; Hashimoto, Y. Bioorg. Med. Chem. Lett. 2002, 12, 3191-3193.

8. (a) Lamberth, C. Pyrazole chemistry in crop protection. Heterocycles. 2007, 71, 14671502.( b) Mc-Donald, E.; Jones, K.; Brough, P. A.; Drysdale, M. J.; Workman, P. Discovery and development of pyrazole-scaffold Hsp90 inhibitors. Curr. Top. Med. Chem. 2006, 6, 1193-1203. (c) Greenblatt, D. J.; Matlis, R.; Scavone, J. M.; Blyden, G. T.; Harmatz, J. S.;
Shader, R. I. Oxa prozin pharmacokinetics in the elderly. Br. J. C. Pharmacol. 1985, 19, 373-378. (d) Culbreath, A. K.; Brenneman, T. B.; Kemerait, Jr. R.C.; Hammes, G. G. Effect of the new pyrazole carboxamide fungicide penthiopyrad on late leaf spot and stem rot of peanut. Pest Management Sci. 2009, 65, 6673. (e) Majumder, S.; Gipson, K. R.; Staples, R. J.; Odom, A. L. Pyrazole synthesis using a titanium-catalyzed multi component coupling reaction and synthesis of withasomnine. Adv. Synth. Cat. 2009, 351, 2013-2023. (f) Naik, S. R.; Harindran, J.; Varde, A. B. Pimprinine, an extracellular alkaloid produced by streptomyces CDRIL-312: Fermentation, isolation and pharmacological activity. $J$. Biotechnol. 2001, 88, 1-10.

9. (a) Elguero, J. in Comprehensive Heterocyclic Chemistry I, ed. Katritzky, A. R. and C. W. Rees, Pergamon Press, Oxford, U.K. 1984, 5, 167-303. (b) Elguero, J. in Comprehensive Heterocyclic Chemistry II, ed. Katritzky, A. R.; Rees, C. W.; Scriven, E. F. V. Pergamon Press, Oxford, U. K., 1996, 3, 1-126. (c) Yet, L. in Comprehensive Heterocyclic Chemistry III, ed. Katritzky, A. R.; Rees, C. W.; Scriven, E. F. V.; Taylor, R. J. K. Elsevier, Oxford, U.K. 2008, 4, 1-15.

10. (a) Merchant, R. R.; Allwood, D. M.; Blakemore, D. C.; Ley, S. V. J. Org. Chem. 2014, 79, 8800-8811. (b) Chen, B.; Zhu, C.; Tang, Y.; Ma, S. Chem. Commun. 2014, 50, 7677-7679. (c) Tarabova, D.; Soralova, S.; Breza, M.; Fronc, M.; Holzerand, W.; Milata, V. J. Org. Chem. 2014, 10, 752-758. (d) Sun, A.; Ye, J.H.; Yu, H.; Zhang, W.; Wang, X. Tetrahedron Lett. 2014, 55, 889-896. (e) Shao, N.; Chen, T.; Zhang, T.; Zhu, H.; Zheng, Q.; Zou, H. Tetrahedron. 2014, 70, 795-799. (f ) Tang, M.; Zhang, W.; Kong, Y. Org. Biomol. Chem. 2013, 11, 6250-6254. (g) Perez-Aguilar, M. C.; Valdes, C. Angew. Chem. Int. Ed. 2013, 52, 7219-7223. (h) Wang, L. ; Huang, J.; Gong, X.; Wang, J. Chem. Eur. J. 2013, 19, 7555-7560. (i) Zora, M.; Kivrak, A. J. Org. Chem. 2011, 76, 9379-9390. ( j) Xie, J.W.; Wang, Z.; Yang, W.J.; Kong, L.C.; Xu, D.C. Org. Biomol. Chem. 2009, 7, 4352-4354. (k) Nair, V.; Biju, A. T.; Mohanan, K.; Suresh, E. Org. Lett. 2006, 8, 2213-2216 
11. (a) Chen, H.; Qian, D. Q.; Xu, G. X.; Liu, Y. X.; Chen, X. D.; Shi, X. D.; Cao, R. Z.; Liu, L. Z. Synth. Commun. 1999, 29, 4025-4033. (b) Clerici, F.; Gelmi, M. L.; Pini, E.; Valle, M. Tetrahedron. 2001, 57, 5455-5459. (c) Lu, R. J.; Yang, H. Z. Tetrahedron Lett. 1997, 38, 5201-5204. (d) Krug, H. G.; Neidlein, R.; Boese, R.; Kramer, W. Heterocycles. 1995, 41, 721-740. (e) Shen, Y. C.; Zheng, J. H.; Xin, Y. K.; Lin, Y. G.; Qi, M. J. Chem. Soc. Perkin Trans. 1995, 997-999.

12. Muruganantham, R.; Mobin, S. M.; Namboothiri, I. N. N. Base-mediated reaction of the Bestmann Ohira Reagent with nitroalkenes for the regioselective synthesis of phosphonylpyrazoles. Org. Lett. 2007, 9, 1125-1128.

13. Muruganantham, R.; Namboothiri, I.; J. Org. Chem. 2010, 75, 2197-2205.

14. Mohanan, K.; Martin, A. R.; Toupet, L.; Smietana, M.; Vasseur, J. J. Methods Three component reaction using the Bestmann Ohira reagent: A regioselective synthesis of phosphonylpyrazole rings. Angew. Chem. Int. Ed. 2010, 49, 3196-3199.

15. Martin, A. R.; Mohanan, K.; Toupet, L.; Vasseur, J. J.; Smietana, M. Regio selective synthesis of 3-carbo-5-phosphonylpyrazoles through a one-pot Claisen-Schmidt 1,3dipolar cycloaddition oxidation sequence. Eur. J. Org. Chem. 2011, 17, 3184-3190.

16. For reviews on organic azides, see: (a) Bräse, S.; Gil, C.; Knepper. K.; Zimmermann, V. Angew. Chem. Int. Ed. 2005, 44, 5188-5240. (b) Moses, J. E.; Moorhouse, A. D. Chem. Soc. Rev. 2007, 36, 1249-1262. (c) Chiba, S. Synlett. 2012, 21-44. (d) Driver, T. G. Org. Biomol. Chem. 2010, 8, 3831-3846.

17. Vijay, N.; Tesmol, G.; George, A; novel synthesis of á-azidocinnamates, $\alpha$-azido- $\alpha$, $\delta$-unsaturated ketones and $\alpha$-azidostyrenes mediated by cerium (IV) ammonium nitrate. Tetrahedron letters. 2000, 41, 3199-3202. 